\title{
An analysis of wind and solar power variability to assess its implications for power grid
}

\author{
Vladislav Shakirov* \\ Melentiev Energy Systems Institute, 130 Lermontov str., Irkutsk, Russia
}

\begin{abstract}
The paper discusses the problem of parallel operation of wind and solar power plants with the power system associated with the influence of power fluctuations on the power quality and stability. A brief assessment of the prospects for the commissioning of the wind and solar power plants in Russia and a description of the associated negative impacts on the power system is given. A methodology for assessing the possible energy production of wind and solar power plants using raw data from weather stations is presented. Based on the methodology, an assessment of some regions of Russia in relation to the variability of wind speed and cloudiness is made. The wind power duration curves are given. An analysis of possible deviations of solar power under the influence of cloudiness is carried out. The effect of geographical aggregation of wind or solar power output to increase the guaranteed power generation and reduce the negative impact on the stability of the energy system is shown.
\end{abstract}

\section{Introduction}

In the energy strategy of Russia for the period until 2030, the summary plan of measures includes stimulation of the integrated development of regional energy based on the use of renewable energy sources [1]. At the end of 2018, the total installed capacity of wind power plants (WPP) amounted to $184 \mathrm{MW}$ and the total capacity of solar power plants (SPP) was 834.2 MW.

The further prospect for the wind and solar energy development in Russia is focused on competitive selection of the most effective projects. It is assumed that more than $2.5 \mathrm{GW}$ of wind power capacity and more than $1 \mathrm{GW}$ of SPP will be commissioned in Russia before 2024 [2].

When planning the development of the regional energy system, one faces the problem of choosing promising technologies for generating electricity and the structure of generating capacities. If there is a high wind or solar energy potential in the studied area, it is advisable to include WPP and SPP on the list of alternatives.

Commissioning of WPP and SPP of high capacity requires careful study of not only economic but also technical efficiency of projects related to the specific features of parallel operation of these plants with the electric power system.

When choosing the capacity of WPP and SPP, it is necessary to take into account a number of features related to the impossibility of accurate forecasting of the energy resources even in a short term; the probability of calm or storm speed of the wind, at which the generation of wind power stops; or the probability of cloudiness, which reduces the flow of solar radiation [3-7].

The volatility of the energy resource leads to fluctuations in the power of the WPP or SPP and the threat of impaired stability of the electric power system [8]. It should take into account the specific features of the joint work of WPP, SPP, and low maneuverable power plants. [9]. WPP and SPP negatively affect the power quality: they can generate higher harmonic components, and create fast voltage fluctuations in the electric power system $[8,10]$. It is necessary to take into account the economic costs of technical measures related to the mitigation of these negative impacts of the WPP and SPP, providing a reserve of generating capacities [3]. Technical difficulties are minimized by limiting the wind power penetration into the grid to $20 \%$ [4].

Areas of prospective siting of wind and solar power plants may have different variability of energy supply. To assess this characteristic, it is reasonable to use longterm archives of meteorological weather stations that are in the public domain. Let us consider the methods of evaluation of electric power generation by WPP and SPP given the weather factors, which essentially influence power generation.

\section{Methodology and software for assessing wind power generation}

To analyze the characteristics of the wind energy potential and wind turbine efficiency, the Wind-MCA computer program is used [11]. Data on wind speed can be imported into the program from the Internet resource https://rp5.ru/, which provides statistically unprocessed

\footnotetext{
*Corresponding author: mynovember@mail.ru
} 
data from long-term measurements of weather stations in Russia. Since measurements at weather stations are carried out up to 8 times a day, to obtain values of wind speed between measurement intervals, an assumption about a linear change in wind speed is made.

Calculation of electricity generation of wind turbines for the considered period is carried out by the expression:

$$
W=\sum_{i=1}^{n} P\left(V_{i}\right) T_{i}
$$

where $P\left(V_{i}\right)$ is the electric power of the wind turbine, corresponding to the wind speed $V_{i}$ on the $i$-th measurement interval, $\mathrm{W} ; T_{i}$ is the duration of the measurement interval, $\mathrm{h} ; n$ is the number of time intervals in the considered period.

The values of $P\left(V_{i}\right)$ for each measurement interval are determined by the power curves of the wind turbine. Wind speed, measured at the height of the weather station weathervane, is reduced to the height of the wind turbine rotor:

$$
V_{i}=V_{\text {meas }}\left(\frac{h_{i}}{h_{\text {meas }}}\right)^{m},
$$

where $V_{i}$ is the wind speed at the height of the wind turbine rotor $h_{i}, \mathrm{~m} / \mathrm{s} ; V_{\text {meas }}$ is the wind speed at the height of the weather station weathervane $h_{\text {meas }}, \mathrm{m} / \mathrm{s} ; m$ is the power coefficient, depending on the season and wind speed.

Fig. 1 shows the Wind-MCA program screen with graphs of wind speed and wind turbine power generation during the month.

The wind turbine power generation curve can be combined in the program with the daily electrical load curve. As a result of the combined curves analysis, information on the share of electricity demanded by consumers in its total generation of WPP for various periods can be obtained.

\section{Methodology and software for assessing solar power generation}

Global solar radiation received by an inclined surface comprises three elements:

$$
Q_{t}=S_{t}+D_{t}+R_{t},
$$

where $S_{t}$ is the beam solar radiation received by an inclined surface, $\mathrm{W} \cdot \mathrm{hr} / \mathrm{m}^{2} ; D_{t}$ is the sky-diffuse solar radiation received by an inclined surface, $\mathrm{W} \cdot \mathrm{hr} / \mathrm{m}^{2} ; R_{t}$ is the ground-reflected solar radiation, $\mathrm{W} \cdot \mathrm{hr} / \mathrm{m}^{2}$.

The value of $S_{t}$ is determined as follows [11]:

$$
S_{t}=S_{n} \cos \theta,
$$

where $S_{n}$ is direct solar radiation on the perpendicular to the beams, W.hr/ $\mathrm{m}^{2} ; \theta$ is the angle of incidence of solar radiation on the surface, rad.

The value of $S_{n}$ is determined according to the Kastrov formula $[11,12]$.

Anisotropic model of J. Hay, Klucher or Perez [13, 14] is used to calculate the sky-diffuse solar radiation coming to the inclined surface.

An isotropic model is used to estimate groundreflected radiation in the majority of research studies [11-14].

The influence of cloudiness on the incoming global radiation on an inclined surface is taken into account by the method of Kuzmin P.P. [12]:

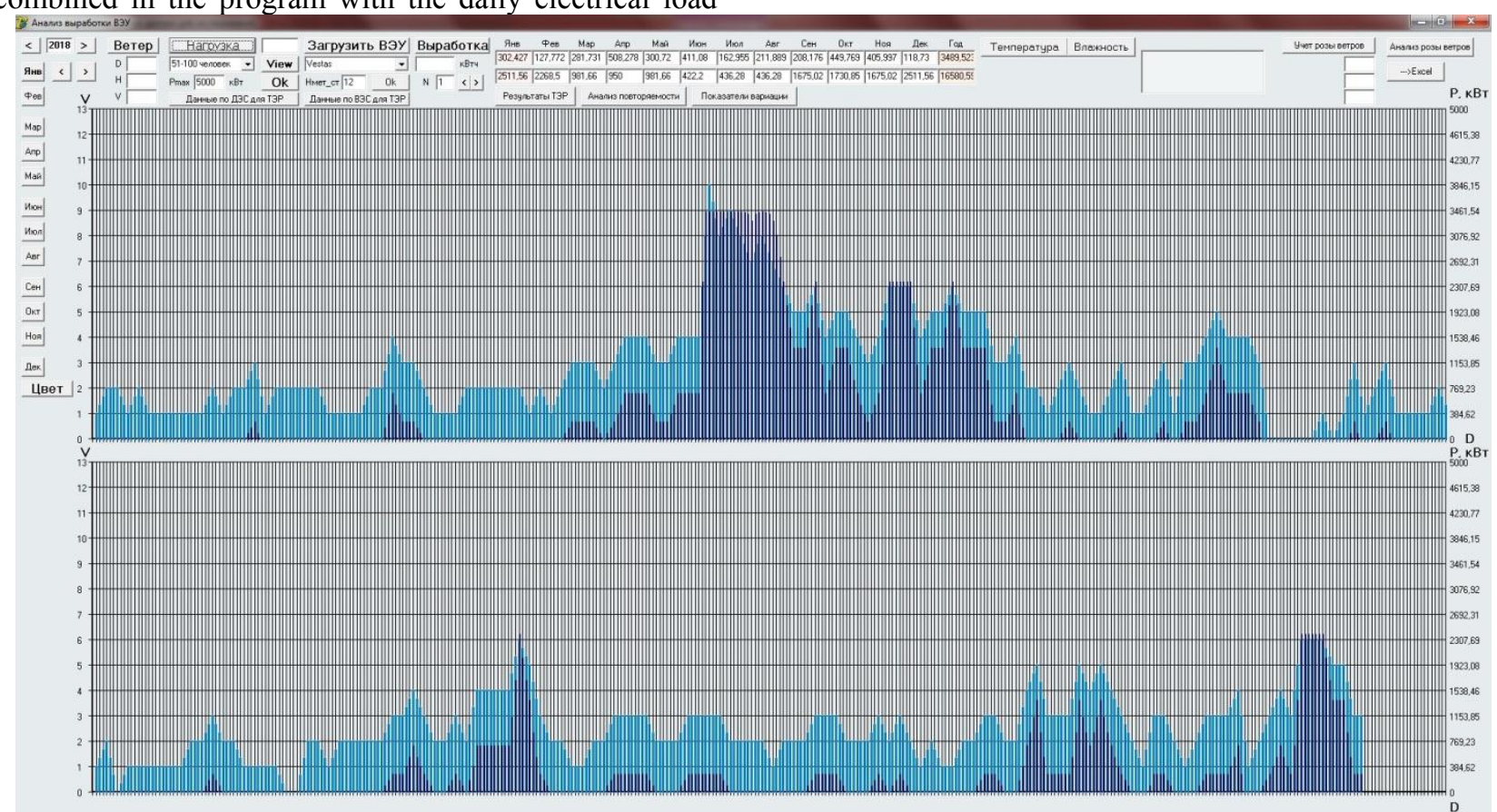

Fig. 1. Screenshot of the Wind-MCA program. Graphs of changes in wind speed (light blue lines) and power generation of wind turbine Vestas V126 4.5 MW (dark blue lines) in January 2018, Ulyanovsk. 


$$
Q_{t s}=Q_{t}(1-A \cdot l-B \cdot(n-l)),
$$

where $A, B$ are empirical coefficients that characterize the weakening of total insolation by low-level, as well as by low and medium-level cloudiness; $l$ - low-level cloudiness expressed as a fraction; $n$ - total cloudiness.

The described technique was implemented by the author in the form of a Sun-MCA computer program [11].

\section{Variability assessment of wind power generation}

Wind speed and energy change significantly over time due to meteorological conditions. The changes occur at all time scales: seconds, minutes, hours, days, months, seasons, years. Understanding these variations and their predictability is key to the integration of wind farms into the power system. An analysis and assessment of the short-term variability of wind energy (from minutes to several hours) are the most important. Hourly, four-hour and 12-hour variations can be predicted and therefore can be taken into account when planning the loading of power plants in the electric power system $[15,16]$.

The impact of diurnal fluctuations in wind speed on power generation was estimated for 3 points at which a wind farm was commissioned or planned. Ulyanovsk WPP was commissioned in 2018, its capacity is $85 \mathrm{MW}$. The commissioning of the Orenburg WPP with a capacity of $350 \mathrm{MW}$ is scheduled for 2030. The commissioning of the Middle Volga WPP in the Saratov region with a capacity of $1000 \mathrm{MW}$ is also planned by 2030.

The Vestas V126 with a capacity of $3.45 \mathrm{MW}$ is used as a wind turbine model. Such wind turbines are installed at the Ulyanovsk WPP. In the Wind-MCA program, the power curve of this wind turbine was introduced. The study employed statistically unprocessed data from meteorological weather stations in Ulyanovsk, Orenburg, and Saratov of 2018.

Table 1 presents the characteristics of the wind energy potential of the three regions, as well as standard deviations of the generated wind energy capacity.

Table 1. Results of wind power variability assessment

\begin{tabular}{|c|c|c|c|c|}
\hline \multirow{2}{*}{ Location } & $\begin{array}{c}\text { Average } \\
\text { wind } \\
\text { speed, }\end{array}$ & \begin{tabular}{c} 
Electricity \\
generation for \\
the year, \\
\cline { 4 - 5 }
\end{tabular} & \begin{tabular}{c} 
MW·h \\
\cline { 4 - 5 }
\end{tabular} & \multicolumn{2}{|c|}{$\begin{array}{c}\text { Daily RMS power } \\
\text { deviation, MW }\end{array}$} \\
\hline Ulyanovsk & 2,49 & 3489,523 & 0,356 & Maximum \\
\hline Orenburg & 3,58 & 7019,963 & 0,559 & 1,581 \\
\hline Saratov & 2,43 & 3100,189 & 0,288 & 1,546 \\
\hline
\end{tabular}

Fig. 2 shows the estimates of power variation coefficients for Ulyanovsk and Orenburg calculated based on meteorological station data of 2018. The coefficient may change significantly during the month. Comparing the estimates of variability in wind power from Tables 1 and Fig. 2, one can conclude that the wind conditions in the areas may differ significantly with respect to short-term variability in wind speed. This factor should be taken into account when choosing the sites for WPP.

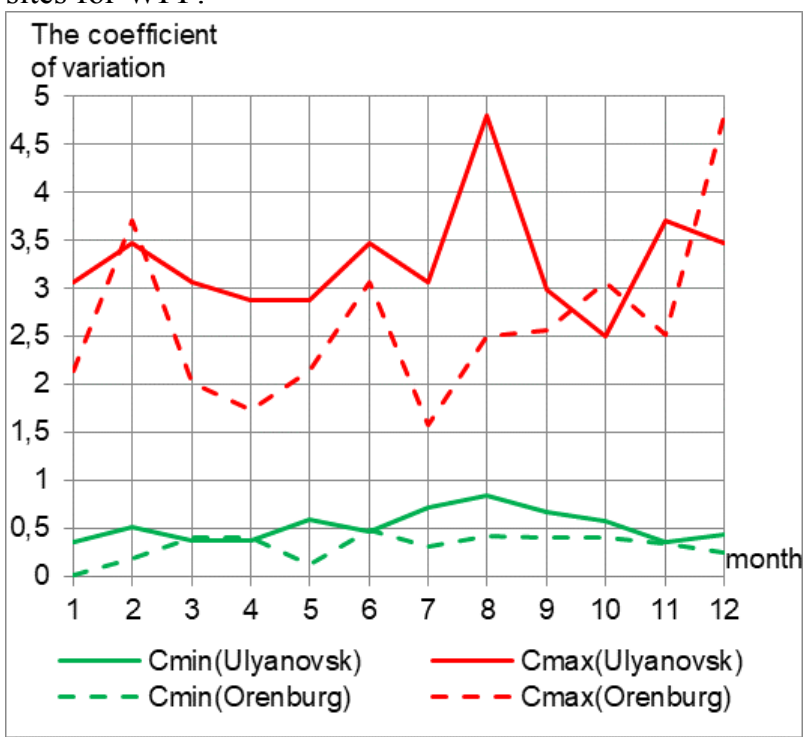

Fig. 2. Changes in the coefficients of variation of wind power calculated for the conditions of Ulyanovsk and Orenburg according to weather stations data of 2018.

When the wind farm sites are distributed at a considerable distance, the effect of balancing power fluctuations occurs. As a result, power fluctuations created by wind farms in the power system are reduced. The geographical distribution of wind farms in the energy system is a very effective way to solve the problem of short-term variability of energy supply. The more wind farms are in operation, the less is the influence of the variability of their generation on the operation of the electric power system.

In addition to reducing fluctuations, the effect of geographical aggregation of the power of wind farms is to increase the guaranteed wind power in the system. Peaks in wind energy production are also reduced if we evaluate the combined output of several wind farms. The effect increases with the size of the area.

To assess the positive effect of aggregation, the load duration curve of wind power plants is used. Such a curve shows the load duration of the plants with a certain power. Fig. 3 shows the load duration curves of the Vestas V126 wind turbine at three points for separate and integrated operation.

Geographical aggregation of wind energy levels the duration curve. In this example, one turbine in Ulyanovsk produces nominal power for 88 hours and zero power for almost 5000 hours. In Orenburg, the wind turbine operates with a nominal power for 167 hours, and the zero output lasts about 2553 hours. If we consider the combined operation of three wind turbines, the maximum power will be only $70 \%$ of the total installed capacity of the three wind turbines, while the minimum wind output will be within 7200 hours. This demonstrates how aggregation on a regional scale leads to increasingly stable wind power generation. To realize the effect of wind energy aggregation, the power grid should be well developed. 


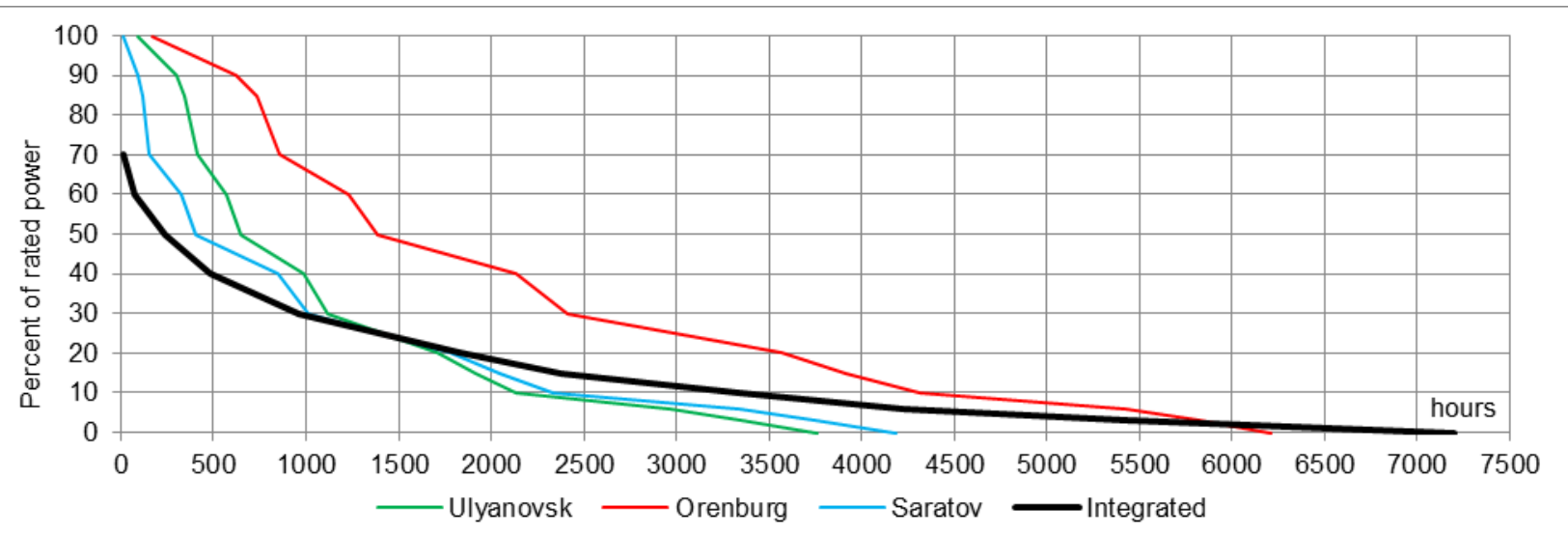

Fig. 3. Comparison of wind power duration curves

\section{Variability assessment of solar power generation}

Electricity generation by SPP changes significantly during the daylight hours. In addition to such factors as the height of the Sun, the angle of incidence of the rays, cloudiness has a significant impact on the incoming radiation. The impact of daily cloudiness fluctuations on power generation has been assessed for 3 regions where SPP are located: Saratov, Orenburg and Samara. There are seven SPP with a total capacity of $195 \mathrm{MW}$ in the Orenburg region. There are 3 SPP in the Saratov region, each with a capacity of 15 MW. One 75 MW SPP operates in Samara.

An analysis was carried out for one polycrystalline panel with an area of $1 \mathrm{~m}^{2}$ with an efficiency of $15 \%$, inclined to the south at an angle of latitude. The SunMCA program was used to process the data on total and lower cloudiness of meteorological stations in Saratov, Orenburg and Samara of 2018. Table 2 presents the calculated estimates of possible electricity generation and average annual cloudiness for the three areas.

The Sun-MCA program was used to analyze possible deviations of solar power generation under the influence of cloudiness (Fig. 4). Table 3 presents estimates of possible deviations in power generation for Saratov. From the estimates presented in tables 2, 3 it can be seen that cloudiness makes a significant contribution to the power generation of SPP.
Table 2. Estimates of solar energy potential and cloudiness for the three meteorological stations in 2018

\begin{tabular}{|l|c|c|c|c|}
\hline Location & \multicolumn{2}{|c|}{$\begin{array}{c}\text { Electricity generated } \\
\text { by a solar panel, } \\
\mathrm{kW} \cdot \mathrm{h} / \mathrm{year}\end{array}$} & $\begin{array}{c}\text { Average } \\
\text { annual total } \\
\text { cloudiness, } \\
\text { coint }\end{array}$ & $\begin{array}{c}\text { Average annual } \\
\text { low-level } \\
\text { cloudiness, } \\
\text { point }\end{array}$ \\
\cline { 2 - 3 } & clear sky & cloud cover & point & 2,92 \\
\hline Saratov & 344,105 & 252,192 & 5,84 & 2,77 \\
\hline Orenburg & 343,034 & 244,444 & 6,07 & 3,00 \\
\hline Samara & 336,492 & 237,974 & 6,24 & \\
\hline
\end{tabular}

Table 3. Estimates of possible deviations in solar power generation for Saratov in 2018

\begin{tabular}{|c|c|c|}
\hline Month & $\begin{array}{c}\text { Maximum deviation } \\
\text { per month, \% }\end{array}$ & $\begin{array}{c}\text { Monthly average maximum } \\
\text { daily deviation, \% }\end{array}$ \\
\hline 1 & 72,4 & 46,4 \\
\hline 2 & 68,8 & 39,7 \\
\hline 3 & 65,8 & 31,2 \\
\hline 4 & 65,0 & 31,9 \\
\hline 5 & 49,0 & 24,4 \\
\hline 6 & 65,5 & 24,6 \\
\hline 7 & 57,0 & 36,7 \\
\hline 8 & 52,3 & 19,3 \\
\hline 9 & 64,9 & 26,3 \\
\hline 10 & 58,4 & 29,6 \\
\hline 11 & 62,5 & 29,7 \\
\hline 12 & 64,7 & 53,7 \\
\hline
\end{tabular}

Fig. 5 shows the graphs of solar power generation at three locations, as well as the graph of joint generation from 14.02.2018 to 17.02.2018.

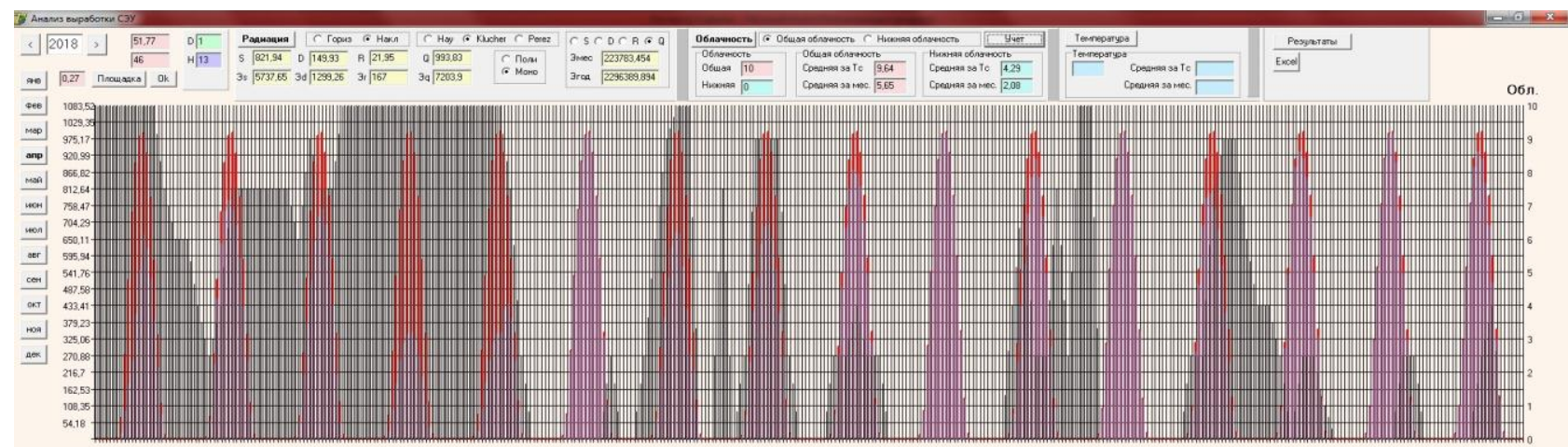

Fig. 4. The effect of cloudiness on the arrival of global solar radiation, April 1-16, 2018, Saratov. The global radiation is shown in purple, gray color indicates the total cloud cover in points from 1 to 10 , red color shows the proportion of radiation lost due to the cloudiness. 


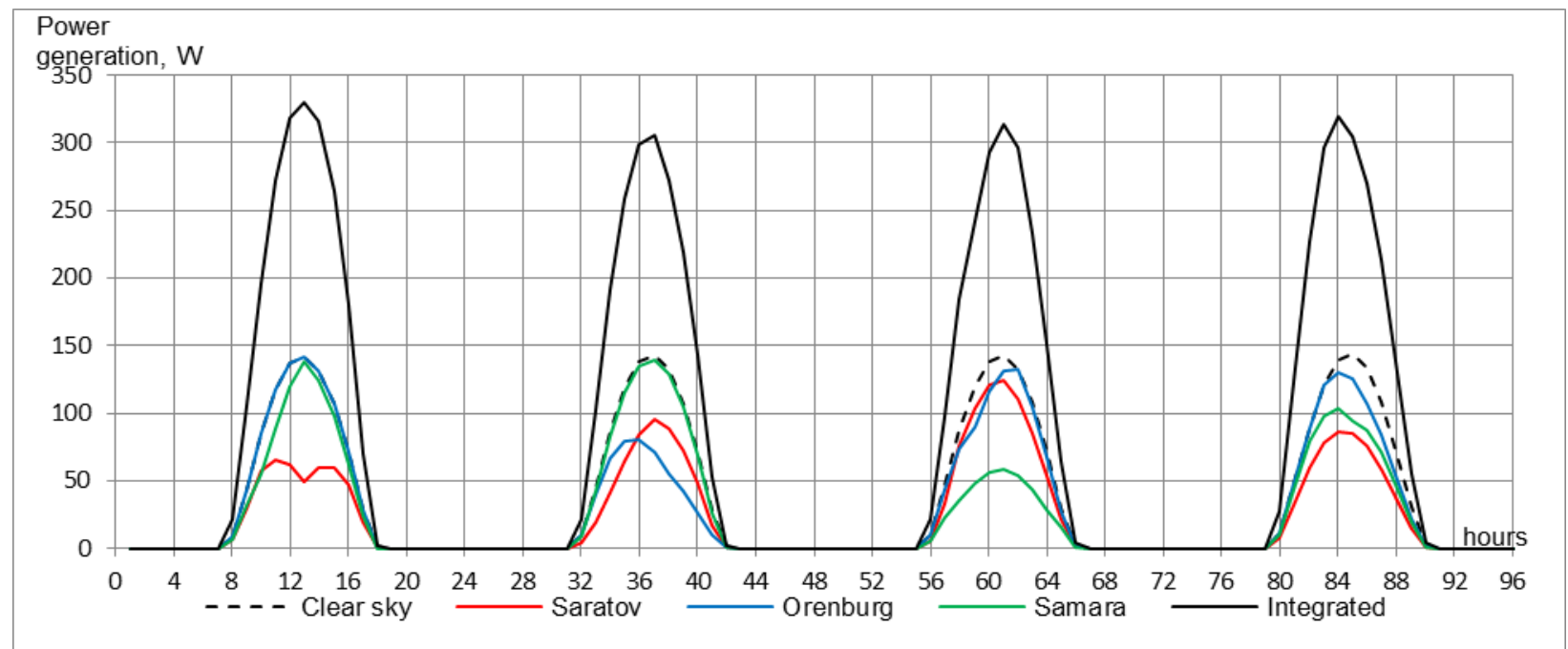

Fig. 5. Solar panel power generation curves in three areas in February 2018

Power generation curves as a result of joint generation of three SPP have smaller amplitude fluctuations.

The developed software allows analyzing possible fluctuations in wind and solar power depending on weather conditions. Sites located at a distance of several tens of kilometers can have noticeable differences in weather conditions and indicators of variability of wind speed and cloud cover. The distribution of stations across the territory makes it possible to reduce power fluctuations during joint production and, thus, reduce negative effects on the stability of the electric power system.

\section{References}

1. Energy Strategy of Russia for the period up to 2030. Approved by the Decree N1715-r of Government of the Russian Federation.

2. Order of the Government of the Russian Federation of January 8, 2009 N 1-r "The Main Directions of State Policy in Improving the Energy Efficiency of the Electric Power Industry Based on the Use of Renewable Energy Sources for the Period up to 2024".

3. G.M. Shafiullah, M.T. Oo Amanullah, A.B.M. Shawkat Ali, P. Wolfs "Potential challenges of integrating large-scale wind energy into the power grid - A review," Renewable and Sustainable Energy Reviews, 20, pp. 306-321 (2013)

4. Xu M. Zhuan X. "Optimal planning for wind power capacity in an electric power system," Renewable Energy, 53, pp. 280-286 (2013)

5. I. Graabak, M. Korpås "Variability Characteristics of European Wind and Solar Power Resources - A Review," Energies, 9, 449 (2016)

6. J. Widén, N. Carpman, V. Castellucci, D. Lingfors, J. Olauson, F. Remouit, M. Bergkvist, M. Grabbe, R. Waters "Variability assessmentand forecasting of renewables: A review for solar, wind, wave and tidal resources," Renewable and Sustainable Energy Reviews, 44, pp.356-375 (2015)
7. S. Watson "Quantifying the Variability of Wind Energy," Wiley Interdisciplinary reviews: Energy and Environment. Early View. 10.1002/wene.95. (2014).

8. J. Sreedevi, K.S. Meera, P. Noor Cheshma, S. Ravichandran, R. Santhanakumar, T. Sumathi, "Grid stability with large wind power integration a case study," 2016 IEEE Region 10 Conference (TENCON), Singapore, pp. 571-575 (2016)

9. V.A. Stennikov, S.V. Zharkov, I.V. Postnikov, A.V. Penkovskii "Integrated energy supply technologies based on the combined heat and power plant and wind farm," Industrial Power Engineering, 11, pp. 57-62 (2016)

10. A. Erduman, H.C. Kılıçkıran, B. Kekezoglu, A. Durusu, M. Tanriöven, "Wind turbine effects on power system voltage fluctuations," 2013 3rd International Conference on Electric Power and Energy Conversion Systems, Istanbul, pp. 1-5 (2013).

11. V. Shakirov "Methodical approach to the estimation of possible energy production by wind and solar power plants using weather station data," E3S Web of Conferences P. 02008 (2019).

12. S.I. Sivkov, Methods of calculating solar-radiation characteristics. Gidrometeoizdat, Leningrad, P. 234, (1968)

13. P.G. Loutzenhiser, H. Manz, C. Felsmann, P.A. Strachan, T. Frank, G.M. Maxwell, "Empirical validation of models to compute solar irradiance on inclined surfaces for building energy simulation", Solar Energy, 81, Issue 2, pp. 254-267 (2007).

14. C.C.Y. Ma, M. Iqbal "Statistical comparison of models for estimating solar radiation on inclined surfaces," Solar Energy, 31, No. 3, pp. 313-317, (1983)

15. E.D. Stoutenburg, N. Jenkins, M.Z. Jacobson "Variability and uncertainty of wind power in the California electric power system," Wind Energ.;17, pp. 1411-1424 (2014)

16. H. Holttinen "Impact of hourly wind power variations on the system operation in the Nordic countries,". Wind Energ., 8, pp. 197-218 (2005) 